\title{
Editorial Introduction: Debating Social Protection
}

\author{
Stephen Devereux and Rachel Sabates-Wheeler
}

\begin{abstract}
1 Introduction
The rapid rise of social protection up the development policy agenda has been startling, even alarming. Part of the explanation is to be found in a growing recognition that social protection can be functional to the achievement of bigger development objectives, including even economic growth and the Millennium Development Goals (MDGs). Mounting evidence that well-designed social transfers can contribute to poverty reduction is appealing to development economists and policymakers who were previously sceptical about social protection's unloved parents, 'social safety nets', which were disparaged during the 1990s as politically expedient, socially stigmatising and fiscally unaffordable in poor countries. The 'safety nets' agenda was vigorously attacked equally from the left (for its social residualism and political cynicism) as from the right (for displacing informal social security mechanisms and creating dependency on unsustainable handouts) until it curled up and died, only to be triumphantly reborn as 'social protection' around the turn of the millennium.
\end{abstract}

So what's the difference? For one thing, the new social protection agenda comes with a fresh array of conceptual frameworks, analytical tools, empirical evidence, national policy processes, heavyweight agencies and big names in development studies aligned behind it. Secondly, social protection appears to be equally amenable to appropriation by the 'right' (who are now inviting the poor to participate in economic growth opportunities with revitalising injections of targeted transfers) and the 'left' (who are hooking their 'rights-based approaches' onto the social protection bandwagon). Thirdly, the social protection agenda prioritises moving people from dependency into productive livelihoods, wherever possible. This concept of 'graduation' distinguishes social protection from the narrower set of purely welfarist measures, which are just a part of the toolkit.

Advocates for social protection fall into two broad camps, which we will label the 'instrumentalists' and the 'activists'. 'Instrumentalist' arguments point to the dysfunctionality of extreme poverty, inequality, risk and vulnerability to the achievement of development targets on which there is broad consensus, currently embodied in the MDGs. For this 'social protection for efficient development' camp, social protection is about putting in place risk management mechanisms that will compensate for incomplete or missing insurance (and other) markets, until such time as poverty reduction and market deepening allow private insurance to play a more prominent role.

'Activist' arguments view the persistence of extreme poverty, inequality and vulnerability as symptoms of social injustice and structural inequity, and campaign for social protection as an inviolable right of citizenship. For these 'social protection for social justice' placard-wavers, targeted welfarist handouts are a necessary but perhaps uncomfortable intermediate step between ad hoc humanitarianism and the ideal of a guaranteed 'universal social minimum', where entitlement extends far beyond cash or food transfers and is based on citizenship, not philanthropy or enlightened self-interest.

Intriguingly, these ideological battles are being fought out around basic and seemingly technical choices in social protection policies and programmes: choices of instruments (social pensions, public works, etc.) and choices in design (targeting vs. universal provision, cash vs. food aid, conditional vs. unconditional transfers). Where a convergence 
between 'economic' and 'social' goals can be demonstrated, consensus is possible - but these opportunities are few and far between. Take minimum wages: in discussions around mainstreaming social protection into Uganda's Poverty Eradication Action Plan in 2003, the editors of this IDS Bulletin argued for a binding statutory minimum wage to be applied to exploited agricultural workers in Uganda's plantation sector. Although the argument was made on social justice grounds, the Ministry of Finance was not convinced until empirical evidence from several countries was produced, confirming that raising wages for underpaid workers does not necessarily result in 'disemployment' effects and can even raise productivity and profits.

Anyone who believes that design choices in social protection programmes - whether to apply conditions, to transfer cash or food, who to target are purely pragmatic technical issues, with decisions based on solid empirical evidence, is missing the point. These are ideological choices, reflecting the 'vision thing' that Kabeer refers to in this IDS Bulletin. Which choices are made, and for what reasons, reflects the kind of society that policymakers and technocrats with power to direct social policy wish to promote. Compare the Government of India's recent decision to enact an employment guarantee for all rural households, with the attitude of the United States towards welfare provision for its citizens. Social protection is self-evidently about a vision of society.

Some of these visions are debated in the papers that follow this Introduction. This issue of the IDS Bulletin revives a tradition of debate that was a feature of its early years, but disappeared some decades ago. The first part of this IDS Bulletin is titled 'Thinking'. Five conceptual frameworks or approaches to social protection are introduced by their protagonists (the World Bank, IDS, OECD, etc). These frameworks are critiqued - commentators were encouraged to be provocative and pithy - and the protagonists are given a 'right to reply' to their critics. Some stirring encounters are the result. In the second part, titled 'Practice', this approach is pursued in some key design choices, including the cash vs. food debate, the conditionality debate, and targeting. The issue closes with two reflective pieces on applications of social protection to vulnerabilities in smallholder agriculture and health (HIV and AIDS).

\section{Thinking: framing the debates}

Five conceptual frameworks are presented and dissected in the 'Thinking' section of this IDS Bulletin: 'Social Risk Management' (World Bank),

'Transformative Social Protection' (IDS Sussex), 'Asset Thresholds' (Michael Carter and Christopher Barrett), the POVNET approach (DAC/OECD), and the 'Universal Social Minimum' (Koy Thomson/ActionAid). Two of these five frameworks are the product of donor agencies, two come from universities and one originates from an NGO. This diversity of sources is encouraging for those who lament that social protection is an entirely donor-driven agenda.

We start with the Social Risk Management (SRM) framework, which has become the most influential approach to social protection in recent years, not least because it has been heavily promoted by the World Bank through its financing, research, training and policy advice. A defining insight of SRM is that poverty and vulnerability are compounded by uninsured risk, so effective risk management will not only stabilise income and consumption but is an investment in poverty reduction. Advocates of SRM make a virtue of its focus on risk and efficiency rather than equity and needs. According to Holzmann and Kozel (this IDS Bulletin), the World Bank's Social Protection Strategy 'is innovative in placing particular emphasis on risk and risk management as a complement to social protection's more traditional emphasis on equity and basic needs'.

To evaluate the SRM framework, we threw the weight of the IDS Director and three IDS students into the fray. Lawrence Haddad opens with a gentle rebuke about SRM's 'failure to engage' with politics, anthropology, geography, sociology and psychology: 'after all, the " $S$ " in SRM stands for social'. As Guenther, Huda and Macauslan then point out, the SRM focus on risk management 'leads to interventions that focus on transitory income shocks rather than on structural determinants of poverty'. Both sets of comments point to SRM's narrow conceptualisation of risk, especially its neglect of 'social risk' and 'irreversibility', which Haddad attributes to the World Bank's 'commitment to mono-disciplinarity'. In their 'right to reply', Holzmann and Kozel acknowledge the 'bias toward economic interpretation' but argue that SRM is open to drawing on other disciplines, and reassert that SRM has shifted the social protection discourse from 'advocacy' toward 'evidence-based policy'. 
The 'Transformative Social Protection' (TSP) framework was devised partly in response to a concern that the increasingly hegemonic Social Risk Management framework was really only about 'economic risk management'. TSP endorses the World Bank belief that risk matters and that social protection can be supportive of economic growth through links to 'prevention' (insurance) and 'promotion' (productivity-enhancing) interventions but complements this by adding a 'social' strand to parallel the 'economic'. Analytically, TSP argues for reconceptualising 'vulnerability' as 'emerging from and embedded in the socio-political context' (Sabates-Wheeler and Devereux, this IDS Bulletin), and requiring interventions that effectively tackle the structural causes of vulnerability. 'Transformative social protection' extends beyond safety nets and welfare handouts, towards supporting citizens to claim social protection from the state as a basic right.

A second group of IDS students was invited to critique Transformative Social Protection. Ken Aoo and his colleagues identify a contradiction in TSP's claims to empower the poor and its prescriptive agenda for transformation, which could be interpreted as patronising at the micro-level and violating national sovereignty at the macro-level. A related critique is that the concept of TSP is too broad and holistic to be operationally useful. Replying to their students, Sabates-Wheeler and Devereux counter that any development policy implies 'meddling' in the politics and culture of other countries, and that TSP is not allencompassing but favours interventions that maximise synergies between (social) 'protection' and (economic) 'promotion'.

Carter and Barrett present an intriguing application of recent economic thinking and analysis to social protection. The basic idea of 'asset thresholds' is that a critical level of assets exists above which people can 'invest productively, accumulate and advance', but below which people are in a 'poverty trap' from which they have no prospects of escape. Empirical evidence plus modelling reveals the profound implications for social protection policy of this bifurcation - for instance, humanitarian assistance that maintains subsistence consumption does not prevent asset depletion and only pushes increasing numbers of people into chronic poverty and a 'relief trap'.

Stefan Dercon critiques the 'unidimensional' focus of the asset thresholds framework on assets, and its neglect of institutional failures (e.g. caste structure) and market failures (e.g. inflexible land rights) that can also induce 'threshold effects'. One implication of all threshold models, noted by Dercon, is that limited social protection resources should rather be expended on protecting people from sliding below the threshold - a genuine 'safety net' function - it is cheaper to keep people from falling down a ravine than helping them to climb out. The corollary is that chronic poverty is unlikely to be reduced at all by small, targeted cash transfers; notwithstanding the current popularity of these social protection programmes. 'Small is not beautiful - it is useless for the poor.' Replying to Dercon, Carter and Barrett emphasise several points of agreement, and suggest a bifurcated policy response: 'large-scale transfers to the very poor and threshold-based social protection for the vulnerable'.

The next conceptual framework in this section is presented by the chair of the POVNET Task Team on Social Protection and Social Policy. Timo Voipio asserts that the OECD/DAC approach to poverty reduction has always been inflected by Nordic values of social development, which produced a multidimensional understanding of poverty and a focus on pro-poor growth that combines 'economic opportunities, social protection and inclusion/empowerment'. In this context, Voipio sees social protection performing two roles: 'as a key element of pro-poor growth but also as a rightsbased responsibility to care'.

Naila Kabeer is not convinced that POVNET thinking on social protection represents a convergence of views, rather than an uneasy compromise between 'members of the club of the world's richest countries', who bring 'somewhat different philosophies and agendas' to the table. Kabeer prises open a key area of disagreement, between 'the World Bank's residualist approach' and the Nordic commitment to universal basic social security, and argues that this reflects two radically different visions of society: the former individualistic and marketbased; the latter group-based and citizen-centred. Ultimately, Voipio appears to agree with Kabeer that the achievement of effective and equitable social protection in any society is a struggle for democratic rights, one that is more likely to be realised through collective action than donor projects.

This is precisely the keystone on which Koy Thomson constructs his justification for a 'Universal Social 
Minimum', by which he means the 'resources, opportunities, rights and power to lead an adequately decent and dignified life, and to participate and advance as a free and equal member in society'. This is an explicitly 'political programme' grounded in human rights and social justice theories, rather than an economic policy debate to be left to 'technocrats'. This approach to social protection requires a broader conceptualisation of poverty and of development, more reminiscent of Sen's 'capabilities' approach and his 'development as freedom' argument.

As 'friendly critics' of the universal social minimum, Sabates-Wheeler and Devereux fully endorse its aspirations but question its practicality, specifically its 'ideological egalitarianism', which risks leaving all poor people poor but equal rather than 'giving some people a hand-up out of poverty'. They also doubt whether the fiscal resources and political constituencies exist in poor countries to provide a minimum package of resource transfers and social rights within national budgets and political processes, or whether this agenda will remain externally induced and financed for years to come. Thomson concedes that some of the most important constituencies for social protection - 'Parliamentarians, civil society organisations, the media, the public' - have been alienated from current debates around social protection, but believes that the universal social minimum could provide a platform for mobilising these constituencies.

\section{Practice: what to do?}

Many issues in the design of social protection programmes that might appear to be mere practical details have provoked fierce theoretical and empirical debates, and ongoing controversy. Three of these design issues are debated here: conditionality, cash vs. food, and targeting. These 'downstream' policy choices bear close scrutiny because they track the same intellectual fault-line that runs through 'upstream' thinking and conceptualisation of what social protection is all about. Crudely, most 'instrumentalists' would line up behind conditional transfers, in either food or cash depending on programme objectives, and fine targeting. Conversely, most 'activists' would argue for unconditional transfers, preferably in cash rather than food, and universal entitlements. For the instrumentalists, a key concern is how to maximise efficiency in resource transfers: conditionality achieves a double impact, and pro-poor targeting minimises leakages to the nonpoor. For the activists, two key considerations are how to maximise freedom of choice (hence unconditional transfers, in cash) and how to entrench social protection as a right (hence universal provision). ${ }^{3}$

We start this section with three very different perspectives on conditionality. Armando Barrientos gives three cheers (or at least two-and-a-half) for conditional transfer programmes, citing empirical evidence that requiring poor parents to send their children to schools and clinics in return for resource transfers does indeed achieve the desired 'double impact' on household consumption as well as propoor investment in human capital. Most of Barrientos' witnesses for the defence come from Latin America, where the public services on which transfers are conditioned are more extensive and more effective than in much of sub-Saharan Africa. This leaves unanswered the question of whether conditional cash transfers (CCTs) are transferable to poorer and institutionally weaker countries in Africa, where CCTs have yet to be widely adopted.

Maxine Molyneux offers an ironic 'Two Cheers for CCTs' (rather than three), welcoming the evidence for 'positive outcomes in children's welfare' but urging caution over some 'overblown claims' made on behalf of conditional cash transfers. Molyneux is especially concerned about adverse gender impacts, agreeing that women are central to these programmes but pointing out that their role is largely confined to 'servicing the needs of others', especially their children. Generally, it is mothers not fathers - who are monitored for compliance with the conditionalities imposed by CCTs, thereby reinforcing women's role as carers of children, while men remain marginalised. Molyneux asks pointedly: in what sense does this empower women?

No cheers at all from Nicholas Freeland, whose depiction of conditional cash transfers as 'economically superfluous, physically pernicious, morally atrocious and politically abominable' is hardly a ringing endorsement. Freeland argues that the word 'conditional' is imprecise, since 'all social transfers are conditional on something'; that the word is reminiscent of IMF and World Bank loan conditionalities and 'smacks of Bretton Woods paternalism'; that conditions are unnecessary because the poor tend to spend some of their social transfers on services anyway (and they should be free to make these choices); and that 
imposing any conditions on social transfers for the poor violates the principle (which most countries have signed up to) that social protection is a 'basic human right'.

Turning next to the thorny issue of cash transfers vs. food aid, we invited Paul Harvey (who is based at the Overseas Development Institute (ODI), which has recently taken up the case for cash transfers in emergencies) to debate with Ugo Gentilini (who is based at the World Food Programme (WFP), where posters in the corridors proclaim: 'We Feed People'). Harvey lists several advantages of cash over food transfers (e.g. cost-effectiveness, choice and dignity), and asserts that many alleged negative features of cash (higher security and corruption risks, lower nutritional impacts, etc.) have been exaggerated. Gentilini argues that the choice of cash or food should not be elevated to a principle - 'cash and food are just instruments and not strategies' - but should be determined by the context and objectives of each social protection intervention. A particular contextspecific concern is how local markets function and how traders, producers and prices will respond to cash and/or food transfers. More generally, Gentilini cites recent empirical evidence suggesting that the 'anti-food movement' has overstated the dependency and disincentive effects of food aid.

Harvey agrees with Gentilini's conclusion that 'cash and food can be complementary' in theory, but points out that in practice food aid continues to drive the global humanitarian system. Until international aid is untied from donor food surpluses and national governments play the lead role in humanitarian response, agency decisions will not be based on evidence and food will continue to be provided even when cash would be more appropriate. Gentilini's riposte focuses on Harvey's belief that cash transfers will inevitably increase and ultimately displace food aid in most emergencies. Gentilini argues that the evidence base on the impacts of cash in emergencies is mixed, that market failures pose a real threat to cash transfer programmes, and that beneficiaries often express a preference for food rather than cash, which it is 'inappropriate' to ignore.

John Hoddinott ends our policy debates by debating targeting with himself - 'Social protection: to target or not to target?' - but reveals his bias immediately by offering 'two vignettes' that illuminate how targeted social transfers 'do indeed deliver a greater share of programme benefits to poor households'. Canada's Old Age Security pension is amusing as well as enlightening: attempting to reconcile equity (universalism) with efficiency (pro-poor targeting), the Canadian government delivers this pension to all its citizens, but taxes it at 100 per cent for the nonpoor! Hoddinott concedes that the various costs of targeting - to administrators, beneficiaries and their communities - can be significant, but he maintains that the savings in reduced leakages to the non-poor usually outweigh these costs. Finally, although this is essentially an economic analysis that refutes arguments for universal provision grounded in social justice, Hoddinott is emphatically opposed to exploiting social stigma for efficient self-targeting: 'this is wrong wrong wrong'.

The closing pair of papers in this compilation apply current thinking on social protection to two key sectors for poor people - agriculture and health but speak to a bigger and urgent need for social protection interventions to be informed by improved analysis. Rebecca Holmes, John Farrington and Rachel Slater argue against the tendency to draw an artificial distinction between 'consumptionsmoothing' social protection interventions designed to address vulnerability in the 'domestic' domain, and 'productivity-enhancing' interventions designed to achieve pro-poor growth in the 'productive' domain. Especially in sectors like smallholder agriculture, where the homestead is also the workplace and the workforce is dominated by family labour, the synergies between the two domains are so strong that an integrated rather than dichotomised approach to social protection and other pro-poor policies is clearly called for.

The final paper rounds off this IDS Bulletin by bringing together fresh ideas for improved analysis and response. Jerker Edström builds a case for reconceptualising 'vulnerability', the defining concept that motivates all social protection, but one that is often inadequately understood and weakly carried through into policy design and implementation. By disaggregating vulnerability into 'embodied and personal biological and psychological dimensions of susceptibility/resistance and sensitivity/responsiveness, with contextual inter-personal and environmental dimensions', Edström implicitly lays out a range of entry points for social protection interventions. How many policymakers consider whether their social protection programmes are aimed at strengthening 
resistance, reducing sensitivity, or addressing the environmental determinants of vulnerability? Edström also questions the usefulness of the household as a unit of analysis and response, when so much social protection is a response to the breakdown of families (e.g. street children) and access to (or exclusion from) support from extended families and communities is a critical determinant of individual vulnerability or resilience. Although Edström is preoccupied with vulnerabilities related to HIV and AIDS, these arguments apply equally to all social protection thinking and practice.

\section{Conclusion}

This selective overview of conceptual frameworks and practical dilemmas in social protection has highlighted how rapidly thinking and practice have moved forward in a few short years, but it has also revealed that a range of conceptual, empirical and policy issues remain unresolved. Some of these issues will resolve themselves, as evidence and experience accumulate, lessons are learned and best practice is institutionalised within agencies responsible for delivering social protection. Other issues pose bigger questions, however. At every level - conceptual frameworks, evidence-building, and policy processes - there are basic disagreements and debates between alternative approaches that are not amenable to consensus or compromise.

\subsection{Conceptual challenges}

All of the conceptual frameworks discussed in this IDS Bulletin are preoccupied with social protection as a response to the economic and social vulnerabilities that poor people face, yet none of these frameworks seems up to the task of comprehensively describing the risk environment and proposing a focused and appropriate set of policy options to mitigate or reduce vulnerabilities. For instance, a fundamental distinction has emerged between conceptual approaches that incorporate structural vulnerability in their understanding of the risk environment, and make social inclusion an explicit objective of social protection programming, and those that do not. Can these two approaches complement each other, or are they inevitably in opposition? More broadly, is there any scope for bringing together the contrasting visions of the 'instrumentalists' and the 'activists', or is this an ideological fault-line that divides the two camps as sharply as that dividing the interests of capital and labour?

\subsection{Evidence gaps}

The evidence base on what works in social protection and what doesn't is patchy, but studies are accumulating and the gaps are rapidly being filled. The 'cash vs. food' debate, for instance, reveals the importance of basing policy choices on a sound analysis of local markets and the articulated preferences of (female and male) beneficiaries, rather than on resource availability or an untested belief that one form of transfer is always best. $A$ similar case for context-specific programming is presented by the debate on conditionalities in social protection, which must take account of the quality and availability of local services on which transfers are conditioned, and should also assess much more carefully the implications for women.

A very different challenge is presented by the evidence on 'asset thresholds'. If these do exist in reality, such that poor people need large 'lumpy' transfers to escape from poverty and 'graduate' from dependence on social assistance, then tiny transfers are indeed 'useless for the poor', and the value in campaigning for a 'universal social minimum' is seriously compromised. The underlying issue here is familiar from social welfare debates: does a rightsbased approach to redistributive transfers inevitably put the brakes on economic growth, and if so, to what extent is each society willing to trade off economic growth against social equity?

\subsection{Policy processes}

A final set of concerns asks the question: where are the drivers of social protection coming from? Too much of the current social protection agenda is designed and financed by external actors - bilateral and multilateral donors, international NGOs, academics and consultants - and not enough is driven by domestic constituencies - national governments, local civil society, citizens. This has unsatisfactory and potentially ominous implications for the ownership of these processes, accountability for delivery and impacts, and political and financial sustainability of social protection programmes. There are simply 'too many pilots and not enough drivers' of social protection, especially in Africa, which has yet again become a laboratory for experimentation, this time with dozens of 'boutique' cash transfer pilot projects that are weakly grounded in domestic policy processes and are rarely institutionalised at scale by national governments. 
The ultimate goal, surely, should be nationally owned social protection policies, underpinned by a 'social contract' between the state and its citizens, where governments acknowledge that social protection is a right for which they are the duty-bearers, and citizens mobilise to demand that this right is

\section{Note}

1 Of course, this distinction is deliberately drawn excessively sharply here. Many social protection 'activists' are (or should be) also preoccupied with efficiency, and most 'instrumentalists' would claim effectively delivered to them. The risk of not moving rapidly in this direction is that social protection will fall as quickly as it has risen, and become in a few years' time just another shooting star in the history of development policy.

to be deeply concerned with equity - indeed, they would argue that the efficient, pro-poor allocation of scarce public resources is a prerequisite for social justice. 